\title{
CREATIVITY AND INNOVATION: IMPLICATIONS OF BUILDING CODES IN THE CITY OF GEORGETOWN, GUYANA
}

\author{
Yerianne Christa Haywood \\ Department of Architecture, Institute of Technology Sepuluh Nopember, \\ Indonesia \\ E-mail: yerianne.h@gmail.com
}

\begin{abstract}
Design Codes have been used as early as the Babylonian Era, where Hammurabi was responsible for some regulations which bore heavy constraints if they were broken. Design codes have since evolved over the years especially considering the experiences of major fires, natural disasters and also the advent of new materials and building techniques. These codes are established by private or governmental committees who are responsible for the development, maintenance, and enforcement of these laws.

Design codes are also known as "building codes" have in some cases been viewed as major constraints on design creativity and innovation in architecture. This refers to the design problems that arise because of these rules and regulations. In the architectural community, the need and importance of building codes are understood and accepted. However, some individuals are of the view that these regulations limit the potential of creativity and innovation in architectural design. Since they are too stringent and do not allow flexibility. While others are of the opinion that they give structure to design and pave the way for good design.

This paper explores the nature of building codes, and creativity in the presence of these constraints. This paper mainly seeks to highlight the impacts of building codes on design creativity in the context of Guyana, South America. Guyana is considered a developing country, as a case study, the paper focuses on the City of Georgetown, the capital city of Guyana. The results indicate that buildings codes can hinder creativity yet they are also needed for setting appropriate standards from design. Guyana has great potential for future development in the building construction industry, where the development of its building codes play an essential role in the creation and guidance of healthy principles of design.
\end{abstract}

Keywords: creativity, design codes, limitations, Guyana, Georgetown 


\section{INTRODUCTION}

\section{Scope, objectives, statement of a problem}

The objective of this paper is to find out the extent to which design codes have an impact on creativity and innovation of buildings within the context of Georgetown, Guyana. The first section of the paper, in a review of the literature, looks at a general background of building codes at an international level, their nature, and development. The link between architectural design and design codes is then discussed in short, along with a description of creativity and innovation and how they relate to limitations or constraints.

In the next section, building codes are evaluated in the context of the City of Georgetown in Guyana, this includes the history, development and enforcement and regulations. A few buildings are then selected to identify the impact of the building codes and creativity with some reference to special considerations of historic preservation. Finally, conclusions are made based on the findings; limitations and constraints experienced during the research are discussed and recommendations for future development are highlighted.

\section{THEORY / RESEARCH METHODS}

\section{A Description of Design Codes and relationship}

Design codes are also known as "building codes", refer to a set of specific standards prepared for use in the design, construction, maintenance and operation of both new and existing buildings (National Council of Governments, 2016). The earliest known influential codes to the regulation of building work date back to the Babylonian civilization almost 4000 years ago. The code of Hammurabi included major implications such as, if a building collapsed and killed the owner, the builder would be put to death; also where there were damaged goods the contractor was instructed to reimburse the owner, among others. Since the time of Hammurabi, building codes have continued to be developed. The experience of loss of a wide range of buildings to fires in the United States during the 1800s further reinforced the need for codes, and thus it has become clear that health, safety, and welfare are the main factors governing why building codes exist (Ching \& Winkel, 2016).

Building codes are more important today because they include guidelines for a wide range of situations in the context of the built environment. Building Codes regulate standards for structures in construction, including sizes, materials, connections and building elements such as stairs, lifts and many others. It also includes services such as electrical, plumbing, mechanical and associated components such as lighting, materials, and appliances. Further, waste management, standards for occupancy, emergencies, and others. Additionally, these codes also include provisions for natural disasters such as fires, earthquakes, hurricanes, and flooding (Banerjee, 2015). Various building types also have codes depending on usage, and more recently stipulations for green buildings and energy requirements. 
The persons responsible for the creation of these codes are private or governmental organizations who are selected to research and compose such documents. These documents exist at varying levels. The International Code Council (ICC) has developed the three following codes; the International Building Codes(IBC), International Residential Building Code(IRBC) and the International Existing Building Codes(IEB) (Ching \& Winkel, 2016). Different countries and states or municipalities within those countries also create codes based on unique features of each place.

It is of great importance that these codes are updated on a regular basis. Therefore, building codes are revised in three-year periods. However, full compliance with building codes does not necessarily mean that a building is invulnerable to threats and vice versa. Codes are updated when there's new knowledge of better applications of construction techniques and/or new materials, natural disasters and research also contribute to the updating of building codes. Additionally, a change of codes could make a building non-compliant if that building has recently been erected or has already been in existence for some time, the enforcement of compliance in such a case creates the need for potentially expensive works (Green, 2012).

Some designers and other persons within the space planning domain are of the opinion that building codes create a constrained environment in which to design and this has a great impact on the potency of creativity and innovation. The Britannica dictionary defines creativity as the "ability to make or otherwise bring into existence something new, whether a new solution to a problem, a new method or device, or a new artistic object or form" (Britannica, 2016). Innovation is closely related to creativity, it involves new ways of looking at products, situations or problems in which creativity is necessary to make this possible. In many cases, creativity and innovation are used interchangeably (CambridgeAssessment, 2018). It has become known that constraints or limitations are inherent to the process of creativity. Humans face many situations every day in which creativity plays an important role in solving problems, these problems may range from simple everyday problems to complex domain-based problems.

Sternberg and Kaufman (2010) state that "creativity represents an 'appropriate solution to a problem or response to a situation"'. They go on to describe the case of evolution where constraints are inherent and the organisms which survive this process are most creative. It seems then that for creativity to be possible there must be the presence of some kind of constraint. Creativity also does not have a base for complete freedom, since constraints always exist in the real world. However, they argue that an individual is regarded as highly creative when his work reflects originality in the given construct (Kaufman \& Sternberg, 2010).

Stokes further reinforces the view that creativity is encouraged through the presence of constraints. She states that "the creativity problem is strategic and structural", which involves constraints that help to both limits searching to ideas that are familiar and also direct a search to ideas more novel. In essence, constraints give structure to a problem space, and a problem space that is well-defined is much easier to be solved in comparison to an ill-defined problem (Stokes, 2006). 
In their book on Architectural Design and Regulations, Imrie and Street (2011) state that "elements of the design and development process, such as the application of legal and quasi-legal regulation, are usually counterpoised by architects as in opposition to creativity, and regarded as anathema to the attainment of a physical building as a work of art". They also go onto mention that more than often architects are against the "idea of regulation" as opposed to the content and purpose of regulatory bodies themselves (Imrie \& Street, 2011).

It can be seen that constraints or limitations are inherent and relevant in the domain of architecture. According to Lawson (2005), design problems arise not only from users, clients and the designer himself but also from legislators which seem to be a more remote source of constraints in contrast to the aforementioned sources. They usually govern factors of safety, utility or appearance and a designer may have to be in compliance in order to be given permission to begin construction. Sometimes there are conflicting perspectives, such that the designer sees legislators as inflexible while in the perspective of legislators the designer may "appear willful and irresponsible" (Lawson, 2005). Creativity, therefore, plays an important role in architectural design for overcoming the challenges which arise in the presence of design codes and regulations.

\section{Research Methods}

The qualitative method is used for research in this paper, it allows a descriptive approach to the research problem and utilizes inductive reasoning to arrive at conclusions based on data collected. This method is used in this paper particularly because of its suitability to the research question. It allows for a holistic approach to the research, which includes multiple and varying perspectives from the sources used. The research question also offers an interesting insight into some issues faced in the architecture and the responses are likely to be relative to the individual's experiences with the issues highlighted in the study. Descriptive research is also open-ended which permits the possible addition of new ideas relevant to the study (Groat \& Wang, 2013). The main instruments for gathering information in this study were literature searching, the use of images for observations and visual analysis and the interview.

\section{RESULT AND DISCUSSION}

\section{Building Codes in the City of Georgetown}

Guyana is located on the northern mainland of South America. Guyana shares international borders with Venezuela to the west, Brazil to the south and Suriname to the east. Georgetown is the Capital City of Guyana, it lies on the low coastal plain of the country bordered on the north by the Atlantic Ocean. Guyana has a rich built heritage accumulating from many years of traditional wooden Architecture. The city of Georgetown is highly recognized for this feature and thus seeks to maintain this identity. 
The Central Housing and Planning Authority(CHPA) was established in the year 1948, as the agency central to the development and regularization of housing in Guyana (Central Planning and Housing Authority, 2018). Proceedings from the Habitat II Conference by the United Nations in 1996 addressed the need for modern building codes to be created and implemented in Guyana (Central Housing \& Planning Authority, 1996). According to the Guyana Chronicle, a local newspaper, the then Minister Housing and Water stated that building Codes were introduced more than 20 years ago but were "never tested and tried and taken to the final stage of ensuring the necessary legislative framework are put in place for enforcement". In March of 2012, the National Building Codes were launched by the Guyana National Bureau of Standards(GNBS). These codes are based on the Caribbean Uniform Building Code(CUBiC) which was developed by the Council of Caribbean Engineering Organization (CEO). CUBiC is standard of codes accepted by Caribbean Nations and upon which they base their own national building codes (Guyana Chronicle, 2012).

The National Building Code of Guyana was called to be reviewed and updated in 2017, the current building codes include 9 Sections which cover Fire Safety \& occupancy, plumbing, foundations and excavation, high-rise buildings. Three other sections look at materials such as Concrete \& Masonry, Structural Steel $\&$ the use of Guyanese Hardwood in Construction. In addition, there exists guidelines and standards for Septic tanks and Latrines. Other governmental organizations are also regulatory bodies through which plans must be approved before construction can begin (Guyana National Bureau of Standards, 2018). There is also special consideration for buildings in historic wards of the city. For new developments and renovations, the National Trust of Guyana is the governing body for actions regarding historical monuments, and areas in the city of Georgetown. The built heritage of Guyana is protected by this agency and their work help to maintain the identity of the city which is based on early traditional wooden architecture (National Trust of Guyana, 2018).

\section{Impact of Building Codes on Design and Innovation}

In Guyana, the National buildings codes do not cover a very large range of topics and are still lacking in content with regards to new building techniques, new materials, and provisions for potentially destructive weather. This affects the architectural output on a whole because even though building codes exist and are enforced to some degree, the codes are not sufficiently detailed to cover a wide range of areas that would allow for a minimum standard of design.

Specifically, in the case of buildings erected in the areas regarded as historic wards, the special guidelines applied by the National Trust of Guyana makes way for an architectural output that also reflects the fabric of the city, its built heritage, and potential. These guidelines seek to regulate material use and appearances of the buildings from aspects renovations to new constructions in historic wards (National Trust of Guyana, 2017). They are not too stringent to be worked with and may even be seen as points where architects can capitalize their creativity. 


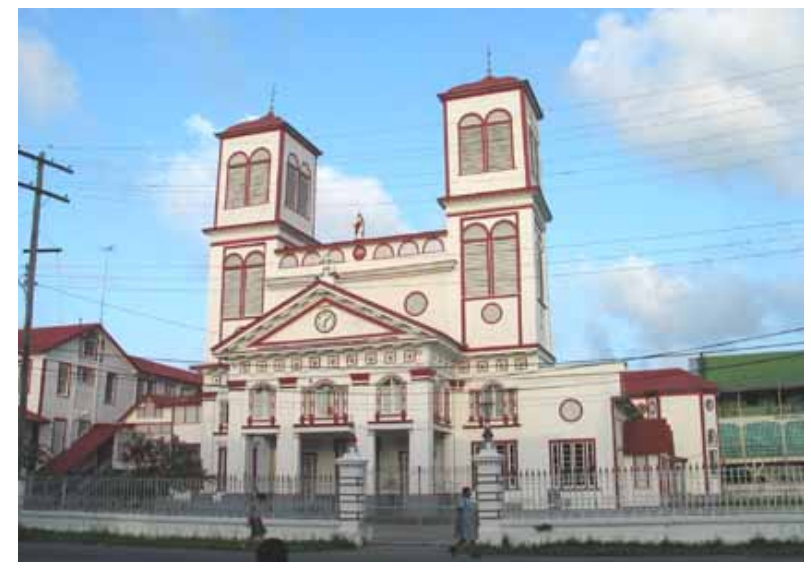

Figure 1. The Old Sacred Heart Church

Source: http://www.sacredheart.gy/history.php

This can be seen in the new erection of the historic Sacred Heart Church (as shown in Figure 2) where the previous original building (as shown in Figure 1) was destroyed by fire. A few years later it was rebuilt bearing a contemporary resemblance of the face and form of the wooden building that previously occupied its space.

Although the new building is made of concrete and incorporates a steel structure to the main body, the appearance of the building uses some features of the previous design. These include the wooden demerara shutters as windows on the higher levels and the twin towards that straddle the main entrance. The color also is generally maintained with the general form of the main entrance mirroring the appearance of the previous structure. This resemblance, however, is predominantly seen on the external appearance, since the many details of timber workmanship to the interior were replaced with the simplicity of a modern style.

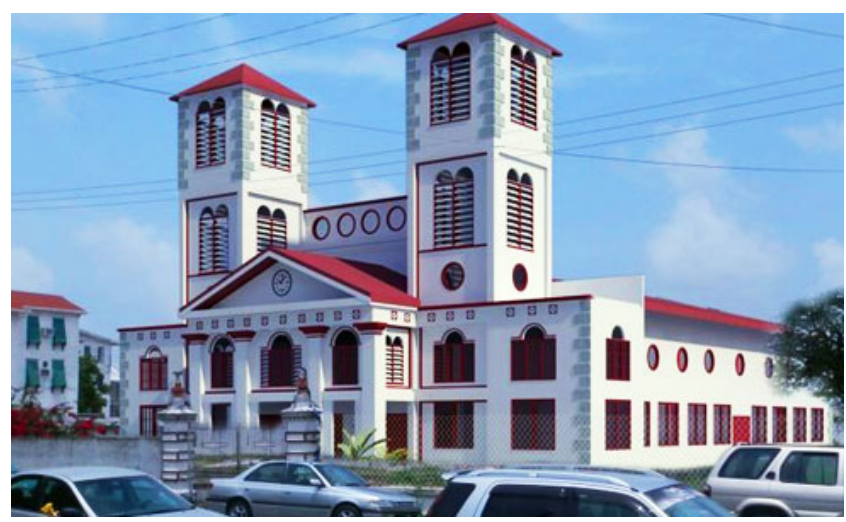

Figure 2. The Rebuilt Sacred Heart Church Source: http://www.sacredheart.gy/history.php 
Another building which was developed in an area within a similar historical context is The New Building Society(NBS). This bank is located in the vicinity of the St. George's Cathedral, one of the oldest and more readily recognized national monuments in the City of Georgetown. Being located in such a historically themed area, it would seem that the architect made considerations for the building's design within the existing context of the surroundings. As stated by the guidelines of the National Trust (2017) new erections should be "harmonious in form, material, siting and scale with reference to the establisblished district character".

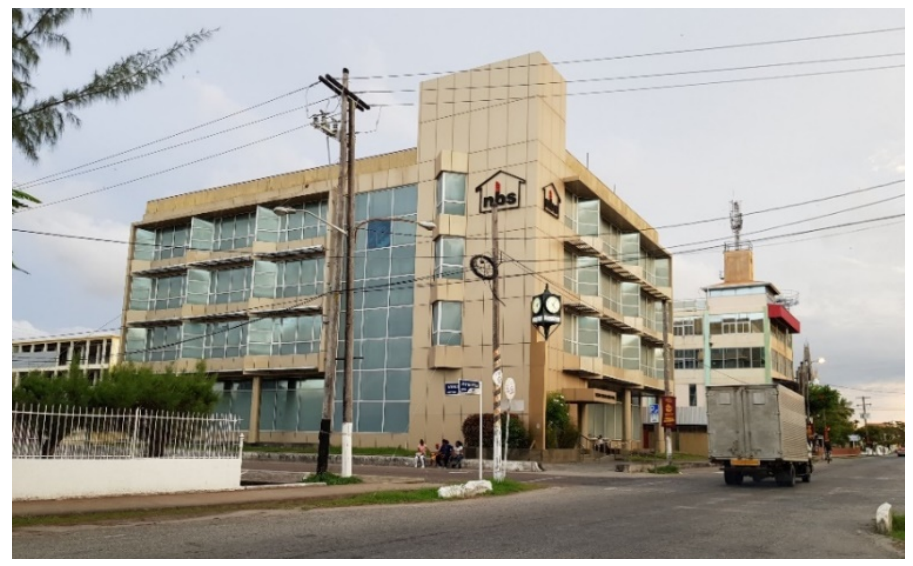

Figure 3. The New Building Society Source: Yancey Haywood

The new erection of the New Building Society (as shown in the figure. 3) does not resemble the gothic renaissance style of the St. George's Cathedral but one main feature readily identified in the appearance of the building is similar to that of another building in the immediate vicinity. The Bank of Guyana located in close proximity of the St. George's Cathedral is a modern structure cladded in some parts with a seemingly folding facade which acts as a device for sun shading to the windows of the buildings. This feature and its color can be seen adapted in the new form of the New Building Society.

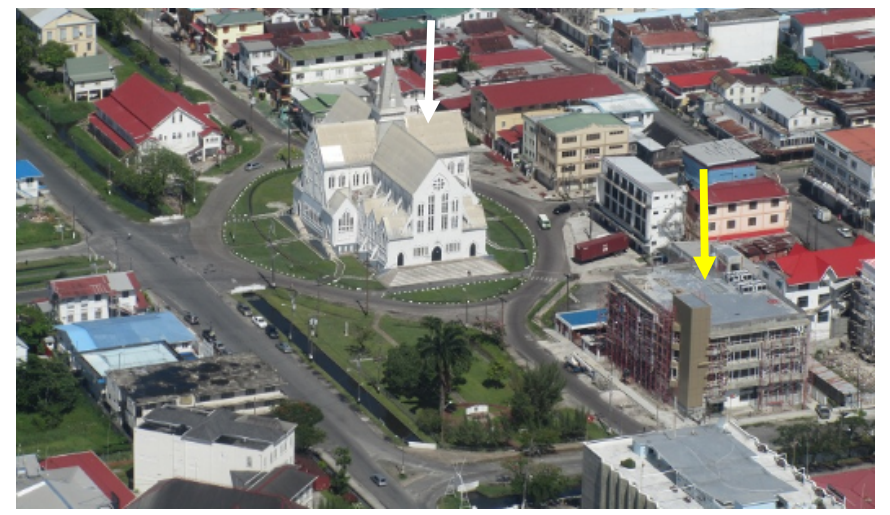

Figure 4. The New Building Society in Juxtaposition with St. George's Cathedral and the Bank of Guyana

Source: http://www.ibike.org 


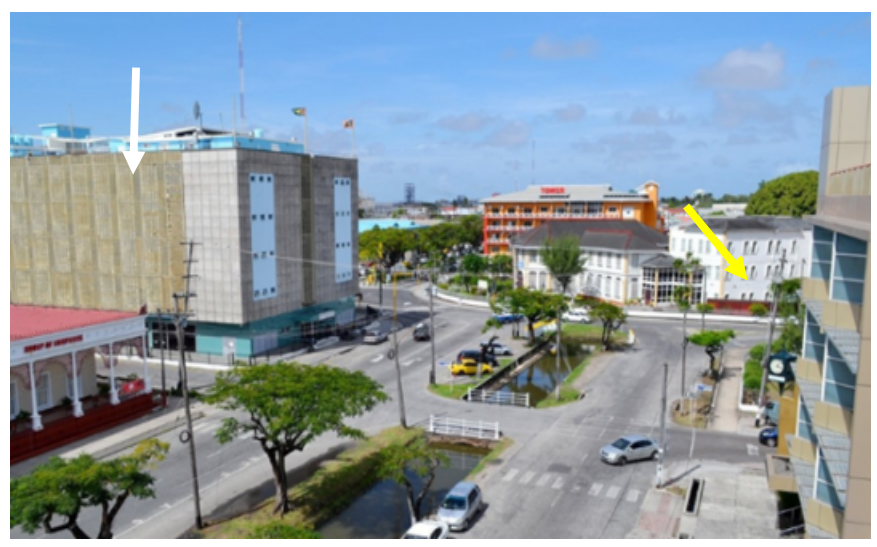

Figure 5. The New Building Society in Relation to the Bank of Guyana Source: 93.1 Real FM

In the City of Georgetown, there is much building which has the same relative design in appearance and in form, this can be viewed as an accepted character or appearance for some buildings. By way of contrast, this can also be perceived as a result of insufficient standards of design which limit the expression of diversity and creativity causing many designers to resort to similar designs. Many of the designs of new erections are predominantly coherent with the modern international stylistic design, bearing large sections of exposed sheets of glass which results in a high strain of air conditioning services because of the climatic context of Georgetown. For this reason, it is possible to see that there exists a disregard or inconsideration to some aspects important in architecture and to the context of Georgetown in terms of culture, identity and thermal comfort. .

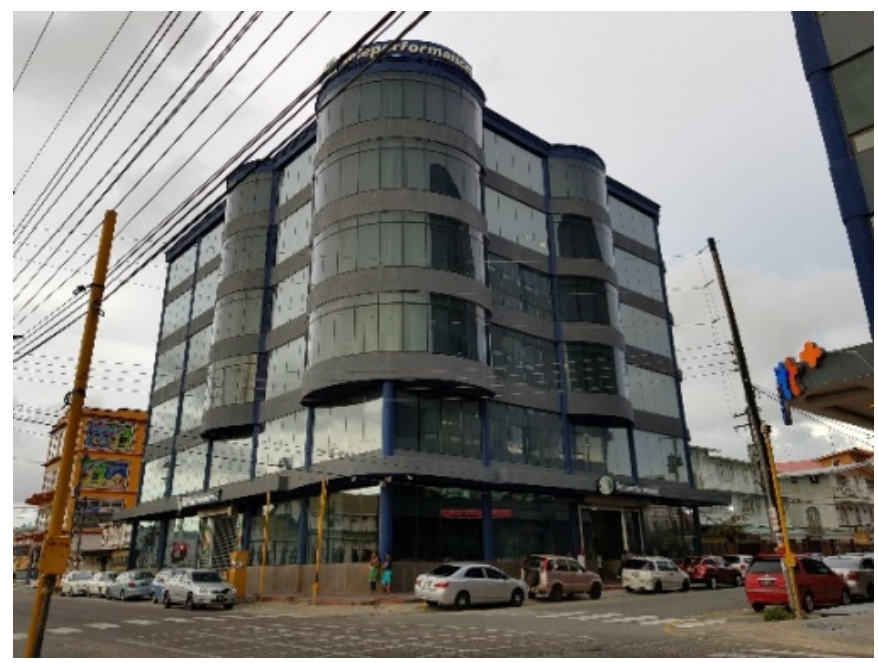

Figure 6. Telecommunications Office Sourece: Image CourtesyYancey Haywood 


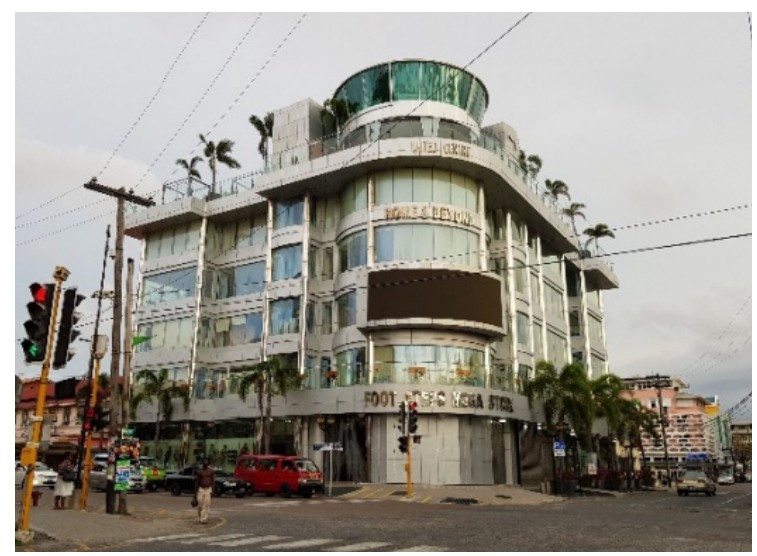

Figure 7. Shopping Centre

Sourece: Image CourtesyYancey Haywood

In other cases, it can be readily seen from the outward appearance of some designs that sufficient thinking or creativity has not been placed in the design process of certain buildings. Since the outward appearance does not readily identify with the kind of activity of functions existent on the inside.

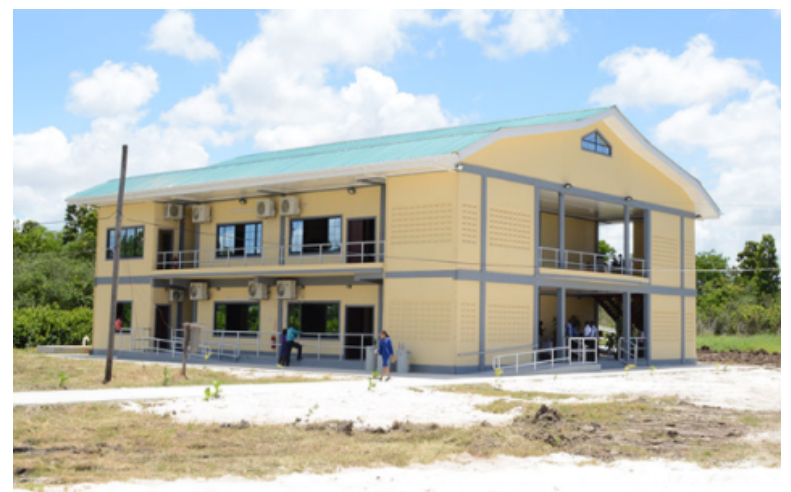

Figure 8. New Lecture Theater Building Source: https://guyanachronicle.com

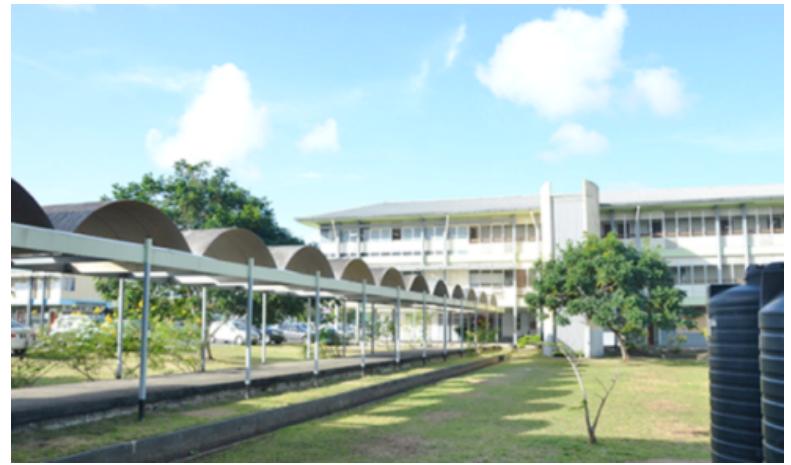

Figure 9. Faculty of Natural Sciences Building Source: http://www.probuddhaeducates.com 
This can be seen on the campus of the University of Guyana where a recent erection of a lecture theater (as shown in Figure 6) has been added. This building is quite unlike all other buildings on the campus and bears no semblance that identifies it as a place for higher learning and motivation of student studies. The mansard roof has no contextual meaning for the University of Guyana or the City of Georgetown, while the air conditioning units have been unthoughtfully placed as if being the last resort or final addition. The color combination also reflects that of primary schools located within the region. For these reasons it can be seen that little thought has been placed on the design process of this building. For a purpose such as higher learning buildings should be reflective of such qualities or characteristics that reflect the pursuit of knowledge as determined by the function of the building.

While there are some apparent issues with the standard of design and building codes in Guyana there are a few buildings which have been exceptional in their response to architecture in the city. It can be seen from these buildings that much thought was placed in the design process and considerations were made not only for the function of the building but also for the cultural and climatic aspects in Guyana.

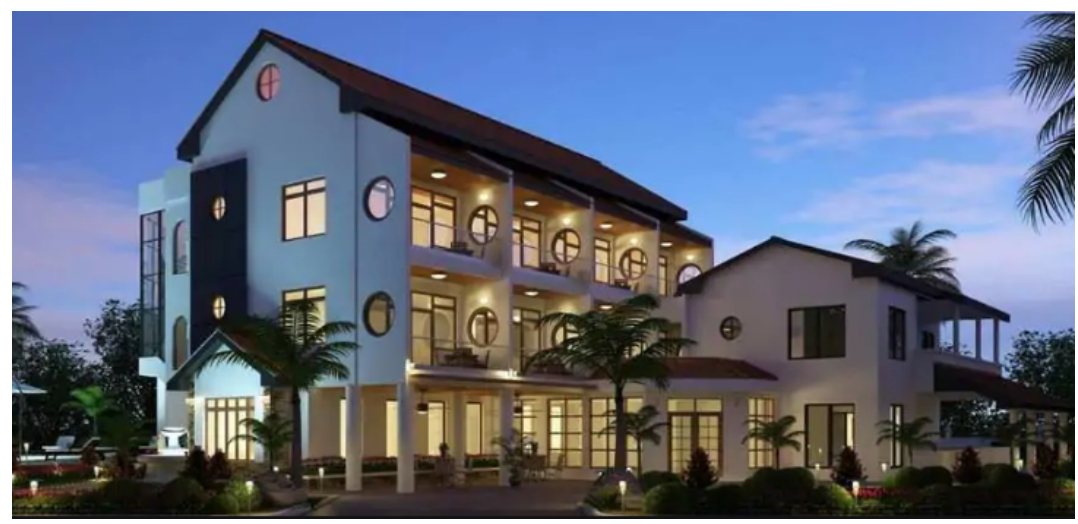

Figure 10. New Design for Herdmanston Lodge Source: https://www.probuddhaeducates.com

The Herdmanston Lodge (figure 7) is a well-known hotel located in the city center, from the appearance of the building its warmth and welcoming atmosphere can almost be felt. The design features a pitched roof as seen in the traditional wooden architecture of Guyana for an effective runoff in the rainy weather. The patio to each room, as can be seen in the picture above, are made private by party walls and also serve the purpose of sun shading. Much thought can be seen in the design of the Republic Bank (figure 8) also which utilizes sunshading devices on the external perimeter of the first-floor windows. 


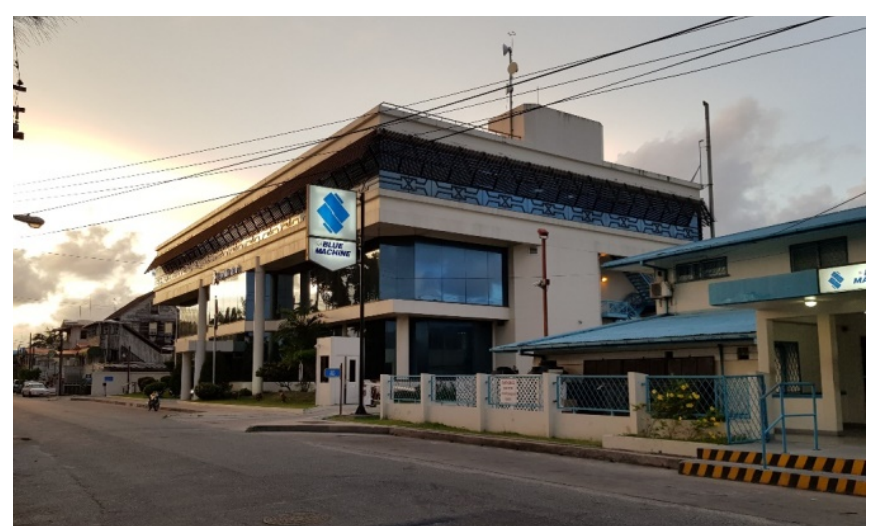

Figure 11. Republic Bank

Source: Image Courtesy of Yancey Haywood

One architect described his challenges in relation to the content available in the building codes of Guyana and his experience with certain aspects of new erections. In these situations, the body responsible for approving the start of construction and enforcement of building codes in regulations showed little to no knowledge in regards to certain aspects and elements of the building. These included the installation and use of new materials such as Aluminum CM cladding, sprinkler systems, elevated pools, underground reservoirs, escalators, and other aspects. There also exists little or no provisions in the building codes for many of these features of the building. Therefore, the hesitance of the responsible body was due to lack of knowledge, possibly from the level of expertise and the insufficiency of the building codes currently available.

Results from this study show that building codes are important and necessary for the regulation or standardization of architectural works. However, building codes create a challenging problem space in which the architect must work through. In some cases, the nature of the building codes can indeed make the design process more difficult if the building codes are too restricted or specific. It can also be seen that in cases where building codes are not updated, do not cover certain aspects or are not properly enforced the result may be that of below standard work wherein little creative skill is utilized. Therefore, there must be a balance maintained, a balance that allows for creative output yet is still flexible enough to be the minimum allowed standard for safety and welfare for occupants. This can only be possible through proper study and assessment of the current state of building codes and an understanding of necessities for future development.

\section{CONCLUSIONS}

It is recognized that building codes are important for the regulation of design activities so that outputs are functional and safe for users and their welfare. It is important to note that one feature of creativity is the presence of constraints, and 
therefore, in essence, innovation and creativity rely on the architects'/designers' ability to create a high standard of design with regards to the design problems created by building codes. In some cases, it is possible the codes can encourage creativity and innovation in design.

It can be seen from the study of some works in the context of the City of Georgetown the unique impact of the existence of building codes. Building codes are necessary in the architectural world as a standard for the identity of the entire urban fabric of the city. The nature of the building codes to a great extent impacts the output in design. If these codes are too stringent the designs may reflect too many similarities and not enough diversity, while also inhibiting the potential for creativity. On the other hand, as in the case of Georgetown where the design codes are not very detailed and insufficient, two main outcomes are possible. First, it is possible for the design output to be at a minimum standard because the minimum standard of the current building codes does not represent a high standard of design for buildings, which can be seen in the new lecture theater on the university's campus. This means that there is not much challenge made necessary to overcome in order to break out of the ordinary or a low standard.

While some designers find it possible to work within these limitations and still deliver quality design it is noticeable that the majority of those buildings are private banks and hospitality buildings which seek a higher standard of building. On the other hand, insufficiency of the building codes causes delays in the construction processes and sometimes the need to verify or justify certain aspects of design which would not be needed if the codes were sufficiently updated and covered a much wider range of categories in the building industry.

Some challenges faced with this study were limited information available online due to not enough digitization of research and other relevant documents. Additionally, the researcher is not currently in a country where this study is concerned, therefore information was received remotely in some cases by indirect sources.

As a recommendation, architects and other individuals with such expertise should be involved in the process of development of building codes. These should be made based on evidence from post-occupancy research, in this way the building codes become evidence-based and not prescriptive and more likely to be flexible enough to work with.

In order for building codes to serve the purpose as intended, there is a need for a single appointed body which would be fully knowledgeable and responsible for not only the development of a detailed set of national building codes but also be able to regulate, enforce and update the national code. To ensure that these codes do not become too constraining there must be adequate research and documentation of the present condition of the construction industry in Guyana and also an analysis and planning for the potential of the city. This would also ensure that architects of the future are able to creatively represent the identity of the city within its urban fabric. Another important factor in regulating a high standard of design is the appropriate licensure of individuals adequately qualified for the design of certain building types.

The public also plays an important role in this matter, they should be made aware of the necessity and importance of these codes and their implications. In this 
way, the public will be able to work with appointed bodies to identify some areas where standards are lacking to help in the demand for better structures more reflective of the culture of the Guyanese people and future development of the built environment.

\section{REFERENCES}

Banerjee, R. (2015) Importance of Building Code. International Journal of Engineering Research and Applications, 5(6), 94-95.

Britannica, E. (2016) Creativity. November 4, 2018 tarihinde Encyclopedia Britannica: https://www.britannica.com/topic/creativity adresinden alındı

CambridgeAssessment. (2018) Developing the Cambridge Learning Attributes.November 5, 2018 tarihinde www.cambridgeinternational.org:

https://www.cambridgeinternational.org/support-and-training-forschools/teaching-cambridge-at-your-school/cambridge-learnerattributes/ adresinden alınd1

Central Housing \& Planning Authority. (1996) Housing and Urban Development in Guyana. Habitat II: The Second United Nations Conference on Human Settlements. Istanbul, Turkey.

Central Planning and Housing Authority. (2018) Central Planning and Housing Authority. November 4, 2018 tarihinde www.chpa.gov.gy: http://www.chpa.gov.gy/index.php?option=com_content\&view=featu red\&Itemid $=63$ adresinden alınd 1

Ching, F. D., \& Winkel, S. R. (2016) Building Codes Illustrated: A Guide to Understanding the 2015 International Building Code (5th Edition b.). New Jersey: John Wiley \& Sons, Inc.

Green, M. (2012) Building Codes for Existing and Historic Buildings. New Jersey: John Wiley \& Sons, Inc.

Groat, L., \& Wang, D. (2013) Architectural Research Methods (Second Edition). New Jersey: John Wiley \& Sons, Inc.

Guyana Chronicle. (2012, March 6) GNBS Launches National Building Codes. November 4, 2018 tarihinde guyanachronicle.com: https://guyanachronicle.com/2012/03/06/gnbs-launches-nationalbuilding-codes adresinden alınd 1

Guyana National Bureau of Standards. (2018) November 4, 2018 tarihinde http://www.gnbsgy.org: http://www.gnbsgy.org/national-buildingcodes/ adresinden alınd1

Imrie, R., \& Street, E. (2011) Architectural Design and Regulation. Oxford, UK: Blackwell Publishing Ltd. 
Kaufman, J. C., \& Sternberg, R. J. (2010) Constaints on Creativity: Obvious and Not So Obvious. J. C. Kaufman, \& R. J. Sternberg içinde, The Cambrige Handbook of Creativity (s. 467 - 482). New York: Cambridge University Press.

Lawson, B. (2005) How Designers Think: The Design Process Demystified (Fourth Edition). Oxford, UK: Architectural Press, Elsevier.

National Council of Governments, o. B. (2016) Codes and Standards Development. November 3, 2018 tarihinde https://www.wbdg.org/resources/codes-and-standardsdevelopment\#rcas adresinden alınd 1

National Trust of Guyana. (2017) Guidelines for the Protection of Monuments and Sites. Georgetown: National Trust of Guyana.

National Trust of Guyana. (2018) November 5, 2018 tarihinde http://nationaltrust.gov.gy: http://nationaltrust.gov.gy/history-ofgeorgetown/historic-cummingsburg/ adresinden alınd1

Stokes, P. D. (2006) Creativity from Constraints: The Psychology of Breakthrough. New York: Springer Publishing Company. 